\title{
Perspectivas metodológicas sobre a hibridização genérica como meio de aproximação à leitura em $\mathrm{E} / \mathrm{LE}$
}

\section{Methodological perspectives on genre hybridization as a means of approach to reading in Spanish as a Foreign Language}

Letícia Joaquina de Castro Rodrigues Souza e Souza Universidade Federal do Ceará (UFC), Fortaleza, Ceará, Brasil. leticiajoaquina@yahoo.com.br

Valdecy de Oliveira Pontes

Universidade Federal do Ceará (UFC), Fortaleza, Ceará, Brasil. valdecy.pontes@ufc.br

Resumo: Neste artigo, tratar-se-á de discutir questões relacionadas à hibridização genérica como meio de aproximação à leitura em espanhol como língua estrangeira - E/LE. Darão suporte a esta proposta, os estudos de Vigotsky (2001), Marcuschi (2008), Genette (2010), Adam e Heideman (2011), Sánchez Miguel, García Pérez e Rosales Pardo (2012) e Lazarini (2013). Escolheram-se os gêneros textual-discursivos do universo de referência dos alunos que captassem outros gêneros, previamente apresentados ou não, mas de fácil reconhecimento, já que são facilmente encontrados e reconhecíveis em Língua Materna. A ideia foi a de expor os alunos a gêneros de fácil reconhecimento em um primeiro momento, os presentes no próprio manual, para depois expô-los a gêneros mais complexos ou elaborados. A atividade proposta referese à hibridização do tipo propaganda-carta-quadrinhos, a partir de um único texto. É importante esclarecer que, no caso da carta, há marcadores genéricos pertencentes a este gênero e, no caso dos quadrinhos, este aparece em sua totalidade, servindo de andaime para a propaganda, alvo principal, devido à manutenção de seu propósito comunicativo. No que 
concerne ao emprego das estratégias de leitura, verificou-se que o texto permitiu aos alunos ativarem uma ampla gama de estratégias, aquelas que atuaram para uma compreensão dos componentes locais, aquelas que atuaram para a compreensão de componentes globais, o uso de predição de inferências e uma alta capacidade de apreciação e réplica em relação ao texto. Percebeu-se que a abordagem proposta pode ser mais dinâmica e acarretar o desenvolvimento de níveis profundos e crítico-reflexivos.

Palavras-chave: hibridização genérica; leitura; espanhol como língua estrangeira.

Abstract: In this article, issues related to genre hybridization as a means of approach to reading in Spanish as a Foreign Language (S/FL) will be discussed. The studies accomplished by Vigotsky (2001), Marcuschi (2008), Genette (2010), Adam and Heideman (2011), Sánchez Miguel, García Pérez and Rosales Pardo (2012) and Lazarini (2013) will support this proposal. The textual-discursive genres chosen were part of the students' background knowledge, as well as other genres which were previously presented or not, but easily recognized, since they are easily found in their mother tongue. The idea was exposing students to genres of easy recognition in a first moment, the ones in the manual itself, and later exposing them to more complex or elaborated genres. The proposed activity refers to hybridization of the advertisement-letter-comics type using a single text. It is important to clarify that, when it comes to the letter, there are their genre markers, and when it comes to comics, this one appears in its totality, serving as a support to the advertisement, which is its main target due to the maintenance of its communicative purpose. Regarding the use of reading strategies, it was possible to verify that the text enabled students to activate a wide range of strategies, those which acted towards a comprehension of the local components, the ones that acted to the comprehension of global components, the use of prediction of inferences and a high capacity of appreciation and reply with relation to the text. It was possible to observe that the proposed approach can be more dynamic and entail the development of deep, critical and reflexive levels.

Keywords: genre hybridization; reading; Spanish as a foreign language.

Recebido em 8 de setembro de 2015. Aprovado em 13 de dezembro de 2015. 


\section{Introdução}

Segundo Adam e Heidemann (2011), os gêneros textualdiscursivos, assim como as línguas, experimentam momentos de tensão entre dois elementos que, ao mesmo tempo, se complementam e se contradizem: a repetição e a variação. A textualidade estaria relacionada a uma força de natureza centrípeta, garantidora da unidade e singularidade de dado texto; já a transtextualidade se relacionaria com as forças de natureza centrífuga, que permitiriam a abertura de qualquer texto para muitos outros textos.

O conceito de textualidade linguística foi definido por Mateus et al. (2003, p. 134) como "conjunto de propriedades que uma manifestação da linguagem humana deve possuir para ser um texto (discurso) ". Isso significa dizer que o referido conceito se relaciona às leis que caracterizam um texto como tal, considerando o conhecimento racional com respeito às condições de produção do texto. A textualidade, pois, contempla do ponto de vista teórico, a natureza e o significado do texto.

Já o conceito de transtextualidade, que foi definido por Genette (2010), designado também pelo autor como transcendência textual, leva em conta todo tipo de relação, seja explícita ou implícita, entre os textos. Faz menção à capacidade inerente de alguns textos de albergar outros textos, passando por um processo de transformação.

Um dos elementos de variação mais significativos é a hibridização. Por essa razão, julgamos ser problemático não considerá-la em sala de aula. A questão não se reduz a classificar os gêneros resultantes de transformações ou hibridizações, e sim, a observar as potencialidades genéricas e seus efeitos para melhorar a qualidade de leitura.

Acreditamos ser oportuno levar para a sala de aula de língua espanhola, por meio das atividades de leitura coletiva, a máxima de que os gêneros são, sim, categorias dinâmicas em variação assim como a língua, e, para que os aprendizes possam atuar em práticas discursivas diversas devem entrar em contato com a presença de um gênero dentro de outro gênero. A partir desta perspectiva, objetivamos discutir questões relacionadas à hibridização genérica como meio de aproximação à leitura em espanhol como língua estrangeira

A ideia é ampliar o leque de interação dos alunos com o texto, já que, segundo nossa experiência docente, parece que, no que tange as atividades de compreensão leitora, boa parte dos materiais destinados 
ao ensino do espanhol como língua estrangeira, assim como materiais de língua materna desconsidera a questão da variação genérica ou da copresença e derivação de gêneros textuais.

\section{Componentes necessários para a análise de práticas de leitura pelo viés da hibridização genérica}

É muito importante dispormos de um mecanismo que nos possibilite realizar uma análise sistemática sobre o que ocorre quando um grupo de alunos enfrenta a leitura de um determinado texto auxiliado pela figura do professor ou da professora, quer dizer, não seria produtivo considerarmos tudo o que foi visto ou lido durante a interação em sala de aula, pois estaríamos mais descrevendo a ação que a analisando. Dessa forma, é necessário estabelecermos unidades de análise precisas que classifiquem o processo e que permitam que outro estudioso possa chegar aos mesmos resultados ou a resultados bem próximos.

Assim sendo, segundo Sánchez Miguel, García Pérez e Rosales Pardo (2012), devemos considerar três eixos importantes para decompor e recompor a interação de modo sistemático. O primeiro deles tem a ver com que conteúdos e processos emergem da interação (o quê); o segundo com quem é responsabilizado pela geração dos conteúdos e a execução do processo; e o terceiro com como se dá a intervenção de uns e outros.

A partir desses três eixos podemos pensar em um modo de descrever padrões sistemáticos de intercâmbio. Sinclair e Coulthard (apud SÁNCHEZ MIGUEL, GARCÍA PÉREZ E ROSALES PARDO, 2012) mencionam alguns componentes recorrentes durante a interação professor-alunos, a saber: o professor se dirige ao(s) aluno(s) com algum questionamento ou com algo que motive a realização de uma ação ( $\mathrm{I}=$ Indagação), logo o aluno responde ou realiza a ação $(\mathrm{R}=$ Resposta) e, depois disso, o professor faz uma avaliação da ação executada pelo aluno (A = Avaliação). Temos, portanto, uma tríade de interação que internacionalmente se considera do tipo IRE (IniciationResponse-Evaluation). ${ }^{1}$ Além desse componente, com o passar do tempo, verificaram-se outras duas possibilidades de interação, a IRF (IndagaçãoResposta-Feedback), na qual o aluno elaborará uma resposta e não somente acionará algo memorizado, a exemplo do primeiro percurso o

${ }^{1}$ Indagação-Resposta-Avaliação. 
controle continua nas mãos do professor. Podemos mencionar ainda o que autores como Wells (apud SÁNCHEZ MIGUEL, GARCÍA PÉREZ E ROSALES PARDO, 2012) caracterizam outras formas de interação, como padrões simétricos, nos quais o aluno dá início à interação e participa ativamente no processo de confirmação. Neste caso, o controle da interação é mais dividido entre professor e alunos ou, por vezes, o aluno pode ter o controle, ainda que parcial, da interação.

Quando pensamos em como se organiza a interação, temos que pensar no papel exercido pelos interlocutores da ação interativa, temos que desvendar um determinado padrão comunicativo que organiza a interação em segmentos com os quais vamos operar. Podemos ter, então, uma estrutura monológica, quando só o professor intervém, uma estrutura do tipo IRE, uma estrutura do tipo IRF e estruturas do tipo dialógica ou simétrica.

Já na dimensão o quê, podemos avaliar a qualidade do que foi produzido na interpretação por meio da identificação das ideias ou proposições nas quais podemos enxergar um acordo e compartilhamento entre as partes.

A dimensão quem está muito relacionada com os tipos de ajuda que falamos anteriormente, quer dizer, o professor ajuda a identificar o tema ou a recordar uma estratégia, por exemplo, ou algum aluno do grupo propõe esse tipo de ajuda.

(...) se consideramos a dimensão $o$ quê, temos que determinar a qualidade do conteúdo gerado durante a interação. Se levarmos em conta a dimensão quem, é possível estabelecer o grau de apropriação (autonomia ou destreza) dos alunos na elaboração desse conteúdo. Finalmente, se focamos na dimensão como, é preciso traçar uma escala que vai desde as estratégias metodológicas centradas na matéria (tradicionais) até aquelas centradas no aprendiz (transformadoras). (SÁNCHEZ MIGUEL; GARCÍA PÉREZ; ROSALES PARDO, 2012, p. 138).

As unidades de análise podem ser mais globais ou mais específicas. A unidade mais específica se chama ciclo e envolve tudo o que é importante para fazer ou dizer para que haja produção de conteúdo válido para os envolvidos na interação. Os diálogos produzidos em sala de aula se materializam em sucessivos ciclos de interação. Para Sánchez 
Miguel, García Pérez e Rosales Pardo (2012), o ciclo constitui uma excelente unidade de análise, pois:

1. Permite-nos diferenciar em ter ideias erradas e ideias aceitas, que são o que conformam o conteúdo público da interação ou a dimensão $o$ quê.

2. Permite-nos ponderar o papel dos alunos e o do professor ao gerar cada uma dessas ideias que são aceitas, isto é, a dimensão quem.

3. E, talvez o mais importante, um ciclo responde a uma estrutura conversacional natural: um movimento de iniciação, um segundo movimento de reação e um final de encerramento. Uma estrutura tripartite que, no entanto, pode ser desenvolvida de múltiplas formas (IRE, IRF e dialógica ou simétrica), e cujo estudo faz parte da dimensão como. (SÁNCHEZ MIGUEL; GARCÍA PÉREZ; ROSALES PARDO, 2011, p. 119).

Os ciclos fazem parte de um segmento mais amplo de análise denominado episódios. Por exemplo, um episódio de avaliação pode ter vários ciclos. Até então, mencionamos duas unidades de análise, ciclos e episódios, que estão em uma relação hierárquica. No nosso estudo, podemos afirmar que a leitura coletiva constitui uma sequência de episódios, quer dizer, tem-se pelo menos dois episódios o de leitura em voz alta e o de avaliação. Sánchez Miguel, García Pérez e Rosales Pardo (2012, p. 121) afirmam que "os ciclos formam episódios e os episódios formam ATAs, por sua vez, compõem o que é chamado usualmente de lições ou sessões". As ATAs (Atividades Típicas de Sala de Aula) são as atividades típicas de sala de aula que se repetem regularmente ao longo das unidades didáticas.

A fim de que possamos deixar mais claras as possíveis unidades de análise de uma interação em sala de aula, achamos por bem exemplificar por meio da tabela de unidades de análise oferecida por Sánchez Miguel, García Pérez e Rosales Pardo (2012, p. 123), na qual podemos ver muito bem, da forma mais global à menos global, o que podemos considerar como relevante para a análise. É importante ter em conta que podemos segmentar a interação operando com diferentes unidades de análise e em cada uma delas podemos explorar os eixos citados anteriormente: quê, quem e como. 


\section{TABELA 1}

Unidades de análise

\begin{tabular}{|c|c|}
\hline \multicolumn{2}{|c|}{$\begin{array}{l}\text { Unidade de análise } \\
\text { Como segmentar a interação? }\end{array}$} \\
\hline \multirow{2}{*}{$\begin{array}{l}+ \\
+ \\
\mathrm{G} \\
1\end{array}$} & $\begin{array}{l}\text { Unidade didática (UD) } \\
\text { Tema de uma disciplina, por exemplo. }\end{array}$ \\
\hline & $\begin{array}{l}\text { Sessão, aula ou lição } \\
\text { Cada uma das atividades temporais em que se desenvolve a unidade didática. }\end{array}$ \\
\hline $\begin{array}{l}\mathrm{o} \\
\mathrm{b} \\
\mathbf{a} \\
\mathbf{l} \\
\mathbf{i}\end{array}$ & $\begin{array}{l}\text { Atividade típica de sala de aula (ATA) } \\
\text { Atividades regulares com um objetivo e um plano de trabalho conhecidos que } \\
\text { conformam cada uma das lições e que se repetem habitualmente ao longo de uma } \\
\text { UD. Por exemplo: a leitura compreensiva, a explicação, a revisão de tarefas, etc. } \\
\text { Cada uma das ATA tem um núcleo de episódios relativamente constante. }\end{array}$ \\
\hline $\begin{array}{l}\mathbf{d} \\
\mathbf{a} \\
\mathbf{d} \\
\mathbf{e}\end{array}$ & $\begin{array}{l}\text { Episódio } \\
\text { Se a ATA é muito complexa, é o caso de diferenciar várias metas distintas que } \\
\text { costumam ser necessárias para o seu desenvolvimento. O desenvolvimento de } \\
\text { cada uma dessas metas principais constitui um episódio que, em geral, tem uma } \\
\text { estrutura de participação reconhecível. }\end{array}$ \\
\hline- & $\begin{array}{l}\text { Ação } \\
\text { Se o episódio é complexo, cabe ainda diferenciar subementas distintas que são } \\
\text { necessárias para alcançar a meta do episódio. Por exemplo, no episódio de leitura } \\
\text { em voz alta, cabe a ação de ler primeiro em voz baixa, identificar palavras novas, } \\
\text { ler por turnos partes do texto, etc. }\end{array}$ \\
\hline & $\begin{array}{l}\text { Ciclo } \\
\text { Conjunto de intercâmbios necessários para que duas ou mais pessoas cheguem } \\
\text { a um acordo ou, pelo menos, acreditem ter chegado a um acordo com relação ao } \\
\text { desenvolvimento de alguma meta (ou submeta). }\end{array}$ \\
\hline
\end{tabular}

Fonte: Sánchez Miguel, García Pérez e Rosales Pardo (2012, p. 123)

Os autores supracitados também fazem um esquema bastante interessante da forma como podemos realizar o procedimento de análise por meio de cinco passos importantes. 


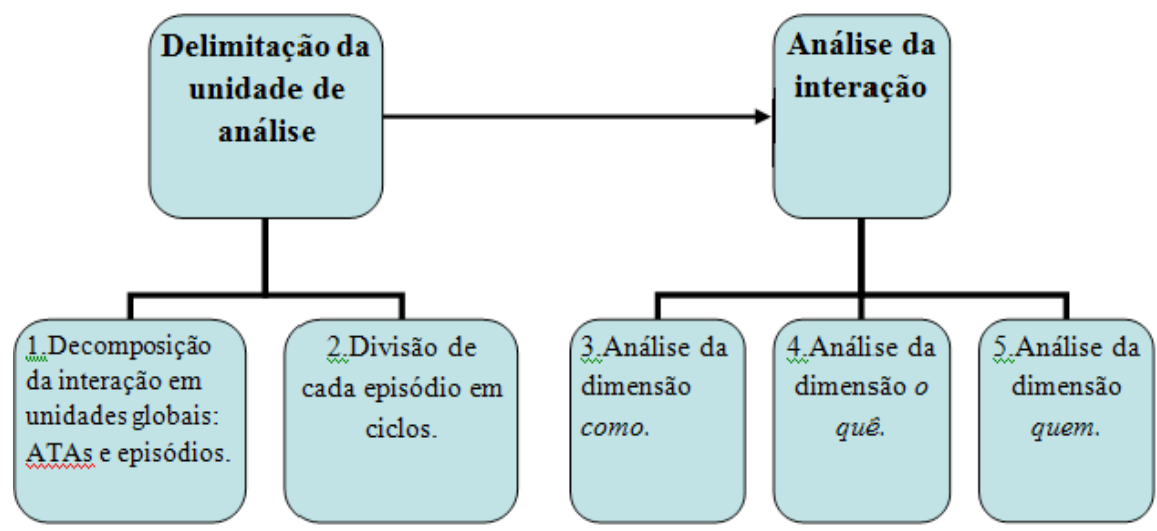

Figura 1: Procedimento de análise

Fonte: Sánchez Miguel, García Pérez e Rosales Pardo (2012, p. 124)

Com o intuito de exemplificar, selecionamos um modelo de texto utilizado no trabalho de Sánchez Miguel, García Pérez e Rosales Pardo (2012) da análise de um episódio de leitura.

\section{TABELA 2}

Representação da relação entre ciclos e episódios

\section{Ciclo 1}

Professor: Então, o lobo é um animal herbívoro, onívoro ou carnívoro?

Alunos: Carnívoro.

Professor: Mas, aqui no texto diz...

Aluno: Que quando está com muita fome come erva.

Professor: Perfeito, que quando está com muita forme come erva, e portanto é também onívoro.

\section{Ciclo 2}

Professor: Onde vivem os lobos?

Aluno: No bosque.

Professor: No bosque, muito bem; mas eles constroem suas casas...Virginia?

Aluna: Em rochas.

Professor: Chamam-se covis e são construídas em covas, em rochas.

\section{Ciclo 3}

Fonte: Sánchez Miguel, García Pérez e Rosales Pardo (2012, p. 120) 
Podemos perceber a presença de dois estratos diferentes. Detendonos na análise do primeiro, é possível perceber que o seu início é marcado pela pergunta do professor (I), por duas intervenções dos alunos e uma do professor, que se referem à elaboração da possível resposta (R), e finalmente o professor encerra o ciclo com um feedback (F). A partir desse esquema, podemos dar início a nossa análise com a estrutura de participação. O contexto de início das interações durante a leitura coletiva, se feitas como no exemplo acima, onde podemos verificar que a estrutura formal comporta os episódios de leitura, seguida do episódio de interpretação-avaliação, com instruções do tipo "Leiam esse texto, que depois vou fazer perguntas".

Acreditamos que considerar as atuações do professor e dos alunos durante a tarefa de leitura em língua espanhola com gêneros textual-discursivos híbridos é uma forma de destacar a importância da interação para o logro da aquisição e da aprendizagem da competência leitora, pois é a através da interação que o input será não somente percebido como relevante, mas também será compreensível para os aprendizes, sobretudo para aqueles que estão começando seus estudos, já que oportuniza descobrir as particularidades da língua e da cultura espanhola por meio da compreensão de que não somente as línguas são variáveis, mas que os textos que veiculam as línguas também variarão para alcançar determinados propósitos comunicativos demandados pela sociedade atual.

\section{Corpus}

Escolhemos os gêneros textual-discursivos do universo de referência dos alunos que captassem outros gêneros, previamente apresentados ou não, mas de fácil reconhecimento, já que são facilmente encontrados e reconhecíveis em língua materna. A ideia era expor os alunos de um curso livre de língua espanhola a gêneros de fácil reconhecimento em um primeiro momento, os presentes no próprio manual, para depois expô-los a gêneros mais complexos ou elaborados. Era importante que os alunos reconhecessem as características dos gêneros transgredidos e dos gêneros transgressores, que pudessem relacionar texto e imagem, além de que percebessem as escolhas linguístico-discursivas e textuais dentro do gênero captado e os efeitos que essas escolhas trazem para a forma de compreender o texto. É 
importante esclarecer que as atividades decorrentes de cada texto selecionado foram adaptadas a partir do trabalho de Lazarini (2013). Com base no estudo da referida autora (2013, p. 93-94), as etapas para o desenvolvimento da pesquisa foram as seguintes:

1) Leitura de um gênero $A$ que captasse um outro gênero $B$ (mais simples, inicialmente, e caminhando para o mais complexo).

2) Identificação do gênero transgressor, por meio de marcas linguístico-discursivas e imagéticas.

3) Em caso de dificuldade da parte dos alunos no reconhecimento do gênero transgressor, apresentação desse gênero no seu formato tradicional para que eles percebessem, com maior clareza, suas regularidades (ou coerções) e os desvios sofridos na mescla.

4) Discussão dos efeitos de sentido produzidos com a transgressão (surpresa, humor, estranhamento etc.) como recurso persuasivo. ${ }^{2}$ (LAZARINI, 2013, p. 93-94).

Seguindo ainda os passos metodológicos de coleta de dados de Lazarini (2013), fez-se necessário elaborar sequências didáticas para as aulas dedicadas à leitura coletiva a fim de detalhar os passos realizados para o desenvolvimento e compreensão de gêneros textual-discursivos híbridos.

${ }^{2}$ Foram feitas adaptações para que as fases pudessem se adequar aos objetivos do estudo. 


\section{TABELA 3 \\ Representação da relação entre ciclos e episódios}

\section{Descrição da atividade}

Duração: 2 aulas (geminadas)

Material: A propaganda e a fotocópia desta para os alunos.

Gênero captado: história em quadrinhos

Objetivos: Ao final da atividade o aluno deverá:

1) Identificar a construção composicional da história em quadrinhos.

2) Observar que o gênero propaganda foi construído por meio do gênero história em quadrinhos e que os elementos presentes no gênero história em quadrinhos aparecem na propaganda.

3) Reconhecer que a propaganda, embora esteja na forma de uma história em quadrinho, manteve sua função comunicativa.

4) Avaliar que, ao se tomarem emprestados a construção composicional e o estilo verbal de uma história em quadrinhos, constrói-se uma interessante estratégia discursiva.

\section{Pré-atividade:}

1) Leitura da propaganda do governo espanhol sobre melhorias no sistema de saúde da unidade 9 do livro Nuevo Avance Básico, página 85.

\section{Pós-atividade:}

1) Discussão sobre os mecanismos persuasivos da propaganda.

\section{Síntese das atividades:}

1) Depois da realização da atividade pretexto, na qual podemos ver a propaganda do governo espanhol sobre melhorias no sistema de saúde da unidade 9 do livro Nuevo Avance Básico, página 85 , em que os alunos devem ler a propaganda, responder as perguntas com ajuda do professor, companheiros ou dicionário e, posteriormente, identificar a nova forma verbal, lhes será apresentado o texto D.

2) O texto D será entregue aos alunos na íntegra.

3) Os alunos farão uma leitura silenciosa do texto e, em seguida, uma leitura coletiva com a finalidade de contrapor o gênero híbrido com o gênero tradicional. Será dado um tempo para a manifestação dos alunos quanto ao texto lido. Apresentação de perguntas orais para que fosse possível verificar como se constitui uma historinha em quadrinhos e por que ela foi utilizada para compor a propaganda:

a) Qual é o assunto do texto?

b) Que cores foram preponderantes no texto? Essas cores têm alguma relação com o produto?

c) Quais são os gêneros textuais presentes no texto?

d) Quais dificuldades você encontrou para o entendimento do texto?

e) Acredita que neste formato a propaganda tem um efeito maior de persuasão do que no formato tradicional?

Fonte: Elaborada pelo autores 


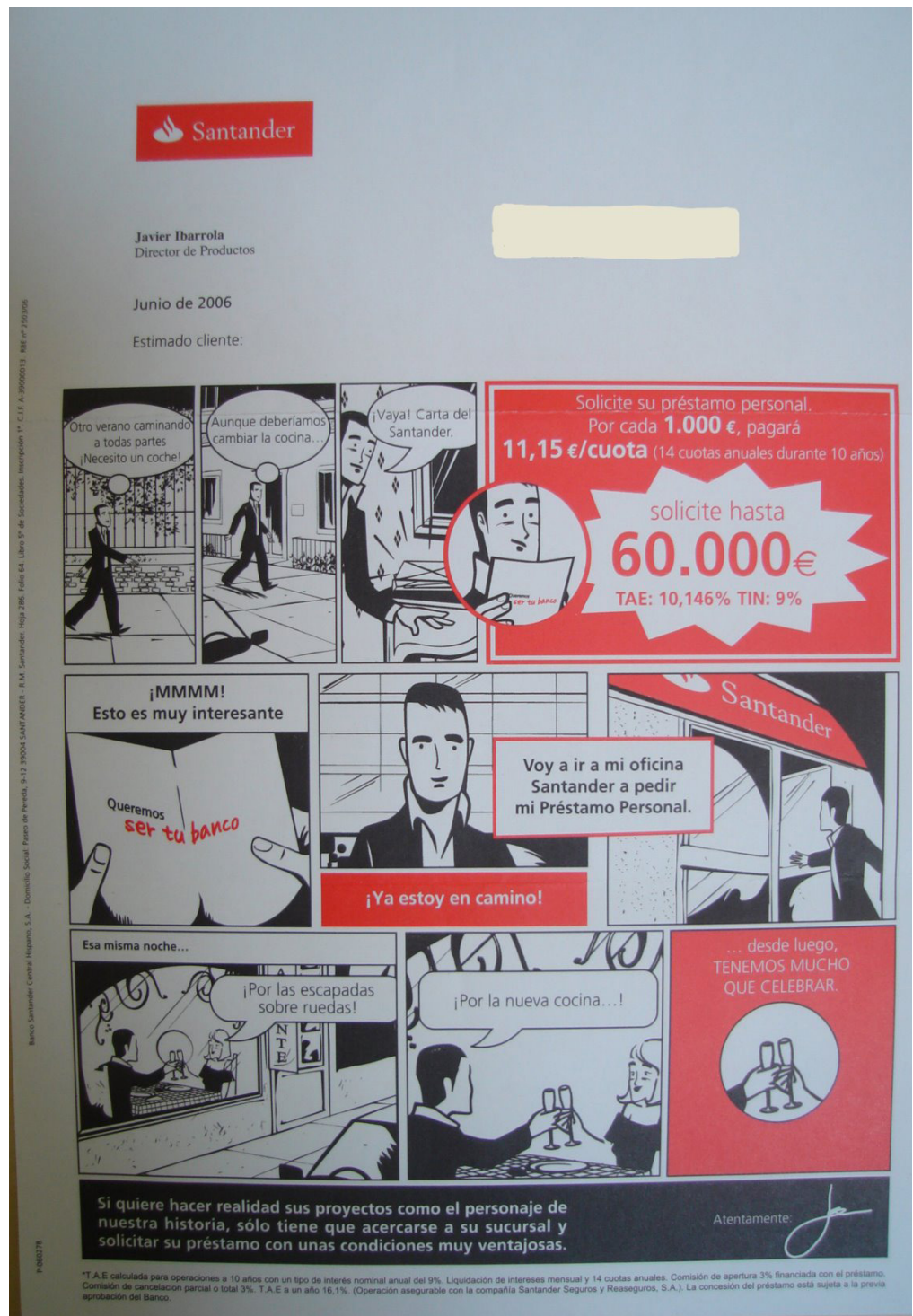

Figura 2: Texto D/ Propaganda Santander

Fonte: Arquivo pessoal 
Para que se possa entender exatamente o texto que consta no anúncio é oportuno colocá-lo em um quadro para que o leitor deste trabalho possa visualizá-lo melhor.

\section{QUADRO 1 \\ Anúncio Publicitário Santander}

\section{Santander \\ Javier Ibarrola \\ Director de productos \\ Junio de 2006 \\ Estimado Cliente:}

\begin{tabular}{|c|c|c|c|}
\hline $\begin{array}{l}\text { Otro verano caminando } \\
\text { a todas partes. ¡Necesito } \\
\text { un coche! }\end{array}$ & $\begin{array}{l}\text { Aunque deberíamos } \\
\text { cambiar la cocina... }\end{array}$ & $\begin{array}{l}\text { ¡Vaya! Carta del } \\
\text { Santander. }\end{array}$ & $\begin{array}{l}\text { Solicite su préstamo } \\
\text { personal. Por cada } \\
1000 € \text {, pagará } 11 \text {, } \\
15 € / \text { cuota ( } 14 \text { cuotas } \\
\text { anuales durante } 10 \\
\text { años) Solicite hasta } \\
60.000 € \text { euros. TAE: } \\
0,146 \% \text { TIN: } 9 \%\end{array}$ \\
\hline $\begin{array}{l}\text { ¡MMMMM! Esto } \\
\text { es muy interesante. } \\
\text { Queremos ser tu banco. }\end{array}$ & \multicolumn{3}{|c|}{$\begin{array}{l}\text { ¡Ya estoy en camino! } \\
\text { Voy a ir a mi oficina de Santander a pedir mi Préstamo Personal. } \\
\text { Santander }\end{array}$} \\
\hline $\begin{array}{l}\text { Esa misma noche... } \\
\text { ¡Por las escapadas sobre } \\
\text { ruedas! }\end{array}$ & $\begin{array}{l}\text { ¡Por la nueva } \\
\text { cocina...! }\end{array}$ & \multicolumn{2}{|c|}{$\begin{array}{l}\text {...desde luego, TENEMOS MUCHO } \\
\text { QUE CELEBRAR. }\end{array}$} \\
\hline \multicolumn{4}{|c|}{$\begin{array}{l}\text { Si quiere hacer realidad sus proyectos como el personaje de nuestra historia, sólo tiene } \\
\text { que acercarse a su sucursal y solicitar su préstamo con unas condiciones muy ventajosas. } \\
\text { Atentamente: }\end{array}$} \\
\hline \multicolumn{4}{|c|}{$\begin{array}{l}\text { *TAE calculada para operaciones a10 años con un tipo de interés nominal anual de } 9 \% \text {. } \\
\text { Liquidación de intereses mensual y } 14 \text { cuotas anuales. Comisión de apertura } 3 \% \text { financiada } \\
\text { con el préstamo. Comisión de cancelación parcial o total } 3 \% \text {. TAE a un año } 16,1 \% \\
\text { (Operación asegurable con la compañía Santander Seguros y Reaseguros, S.A). } \\
\text { La concesión del préstamo está sujeta a la previa aprobación del Banco. }\end{array}$} \\
\hline
\end{tabular}

Fonte: Elaborado pelos autores

\section{Análise dos dados}

A atividade fazia referência à hibridização do tipo propagandacarta-quadrinhos. Foi utilizado um único texto que nomearemos de D. É importante esclarecer que, no caso da carta, há marcadores genéricos pertencentes a este gênero (modelo do gênero) e, no caso dos quadrinhos, 
estes aparecem em sua totalidade, servindo de suporte para a propaganda, alvo principal, devido à manutenção de seu propósito comunicativo, o que para Marcuschi (2008) é o elemento mais representativo para uma possível classificação genérica.

No que concerne ao assunto do texto, alguns grupos ficaram divididos, já que alguns alunos se concentraram em elementos globais para determinar o assunto do texto, qualificando-o como empréstimo pessoal e outros se concentraram mais nos elementos locais, classificando o assunto como a história do personagem em quadrinhos.

No entanto, chamamos atenção para a primeira tentativa de classificação genérica, quando a aluna afirma que é uma carta mandada pelos bancos. Além disso, a aluna percebe que não se trata de uma carta comum, já que diz que esta se vale da propaganda para mostrar os benefícios em contratar um empréstimo pessoal pelo banco Santander.

TABELA 4

Texto 21 - Assunto do texto D

\section{Texto 21: Assunto do texto D}

\section{Ciclo 1}

Profesora: Para el grupo uno. ¿Cuál es el asunto del texto?

Alumno 17: Préstamo.

Alumno 1: Empréstimo. Dinero. Cómo conseguir dinero en lo banco.

Profesora: Por el banco.

Alumno 9: Santander.

Profesora: ¡Vale, muy bien! ¿Vosotros habéis escuchado lo que ellos han dicho?

Alumnos: Sí.

\section{Ciclo 2}

Profesora: ¿Sí? ¿Todos? El grupo dos, ¿qué pensáis que es el asunto del texto?

Alumna 12: Es una propuesta...

Alumna 14: Es una propuesta de servicio de préstamo de un banco.

Alumna 12: de banco Santander.

\section{Ciclo 3}

Profesora: Vosotras dos.

Alumna 18: Es sobre un hombre que estaba intentando una forma de ganar dinero y conseguiu con el préstamo.

Alumna 8: Un préstamo personal, una propaganda del banco Santander.

Profesora: ¡Muy bien! 


\section{Ciclo 4}

Profesora: Vosotros dos...

Alumno 9: Un hombre que quiere cambiar la cocina. ¿Adquirir? Adquirir un coche y ver en el banco Santander una posibilidad de resolver sus sueños.

Profesora: Alumna 11.

Alumna 11: Un convite del banco Santander de un préstamo personal a un cliente, né? Que estaba precisando de cambiar la cocina. ¿Cómo se diz? Otras cositas. Acho que ele acabou fechando o negócio, pegando o empréstimo e se alegrando, vindo a celebrar o empréstimo.

Profesora: El préstamo, ¿vale? Puedes decir Alumna 14.

Alumno 1: El préstamo.

Profesora: Préstamo. Empréstimo no. Solo préstamo.

Alumna 14: En verdad ese...esa carta es una de aquellas cartas que los bancos envían a los clientes ofreciendo servicio. Divulgando la utilización de un servicio.

Profesora: Vale.

Alumna 14: Utilizan el lenguaje de propaganda mostrando los beneficios de adquirir un préstamo como este.

Fonte: Gravação do dia áudio do dia 16/04/2014

Com o intuito de que os alunos conseguissem construir um conteúdo público eficaz e compartilhado por todos, insistimos em perguntar qual, de fato, seria o assunto do texto. Os alunos, a partir dos elementos textuais e de seu conhecimento enciclopédico, chegaram à conclusão de que o assunto do texto realmente era oferecer um empréstimo pessoal e de que a história servia para ilustrar como o cliente poderia utilizar o dinheiro obtido com tanta facilidade.

Conseguiram, pois, distinguir o conteúdo primário do conteúdo secundário, tendo em vista que o mais importante não era comprar um carro novo ou reformar a cozinha e, sim, a possibilidade de realizar os sonhos dos clientes por meio de um empréstimo pessoal, pouco importando a circunstância que serviu de exemplo.

Os alunos conseguiram alcançar um alto nível de compreensão do texto, tendo em vista a realização de uma leitura crítica e a análise de diferentes tipos de informação, o que resultou em um processo ativo e consciente de integração. Foram, portanto, alcançados os níveis de compreensão profunda e crítico-reflexivo nesta atividade.

Outra questão que nos pareceu importante foi pedir para que os alunos relacionassem as cores presentes no texto com o grau de importância das informações. As cores preponderantes eram vermelha, preta e branca. 
Para todos, pareceu evidente que a cor vermelha se associava à cor do banco. O que nos deixou entusiasmados foi o fato de os alunos perceberem que a cor vermelha era empregada nos balões cuja informação era mais relevante. $\mathrm{O}$ branco faz parte da cor do banco e da composição dos quadrinhos que foram colocados em branco e negro para ressaltar as informações concernentes ao banco.

Para Field (2004), uma das funções dos componentes visuais é enfatizar os pontos centrais do texto, bem como oferecer reforço visual para um assunto. Os alunos de $2^{\circ}$ semestre de língua espanhola observaram muito bem a função dos componentes visuais para a construção dos sentidos do texto. Para nós, isso se dá pela sua experiência leitora em língua materna e pela transferência de procedimentos de leitura de uma língua para outra, o que reforça um dos pressupostos assumidos por nós no que diz respeito à aquisição e à aprendizagem de uma língua estrangeira, quando se aceita que as etapas ou os processos pelos quais se adquire a língua estrangeira são muito semelhantes às etapas e aos processos pelos quais os aprendizes adquiriram suas línguas maternas, sobretudo, no que concerne à leitura, tendo em vista que, para Vigotsky (2001), as funções psicológicas superiores, entre elas a leitura, são produtos do desenvolvimento cultural e intervém para a sua formação os processos de mediação sociocultural, tão determinante para o seu desenvolvimento.

Corroborando a ideia defendida por Adam e Heideman (2011), da abertura de um texto para muitos outros textos ou, melhor dito, das forças que permitem a abertura de um texto para a incorporação de muitos gêneros, os alunos foram conscientes disso e reconheceram que o texto D era composto por três gêneros textuais distintos que exerciam papéis distintos para a construção do sentido. Reconheceram a presença da carta a partir de seus elementos constitutivos como remetente, data, saudação e despedida, que compuseram a estrutura do texto, assim como reconheceram a presença de uma história em quadrinhos e da propaganda. 


\section{TABELA 5}

Texto 24 - Gêneros textuais presentes no texto D

\section{Texto 24: Gêneros textuais presentes no texto D}

\section{Ciclo 1}

Profesora: A ver, ahí yo empiezo por aquí. ¿Cuáles son los géneros textuales presentes en el texto?

Alumna 3: Anuncio publicitario.

Alumno 1: Es una carta.

Alumno 13: Dentro del texto tiene una carta, ¿sí?

Profesora: Vamos a pensar del macro al mínimo. De modo general, ¿cuál es la primera cosa que os llama la atención en el texto? Si vosotros fuerais a clasificar, digamos: Este textos es un...

Alumnos: Un anuncio.

Profesora: Un anuncio.

Alumna 12: Es una mala directa. Es igual para todas...

Alumna 14: Es un padrón.

\section{Ciclo 2}

Profesora: Bueno, ¿qué más? Es....ahí vosotros diríais de modo general que se trata de un anuncio. Vosotros tenéis que mirar todo el texto.

Alumno 1: Sí.

Profesora: Los elementos que dicen esto es una carta, esto es un anuncio, esto es lo que sea.

\section{Alumnos: Comics.}

Profesora: Esto es un comics. Exacto. Yo quiero que vosotros me digáis para mí es...yo necesito sabes cuáles son los elementos en el texto que son determinantes para decir eso es una carta, eso es un anuncio o eso es un comics.

Alumna 14: Es una carta que usa de varios recursos para convencer al cliente.

Profesora: Por ejemplo.

Alumna 14: Como por ejemplo los comics, la tarjeta roja con comics con valores, el color del banco y la idea de compras. De que puedes adquirir a través de un préstamo como este.

Alumno 1: Pero tiene una cosa que tenemos que ter atención. Por ejemplo: en el topo del texto tenemos el nombre del director, la fecha, una saudación estimado cliente y en el final tenemos una asinatura.

Profesora: Una firma.

Alumno 1: Una firma. Entonces... 
Alumna 12: Yo pienso que es una carta.

Alumna 14: Es una carta de uso para divulgar los servicios del banco.

Alumno 1: Una mezcla. ¿Mezcla? Una mezcla de géneros.

Profesora: ¿Y cuáles son los géneros que están ahí?

Alumnos: Carta, comics y anuncio.

\section{Ciclo 3}

Profesora: Si vosotros pudierais poner una jerarquización, ¿cuál es el...?

Del género más importante al menos importante.

Alumnos: Anuncio.

Profesora: Anuncio. ¿Después?

Alumnos: Carta.

Profesora: Carta. ¿Y?

Alumnos: Comics.

Fonte: Gravação do dia áudio do dia 16/04/2014

Ao serem perguntados sobre a capacidade persuasiva do texto, os alunos reconheceram que a composição do texto o torna extremamente persuasivo, tendo em vista que a história em quadrinhos dentro da configuração da propaganda serve para que o público-alvo reflita sobre sua história e suas necessidades, fazendo-o pensar mais fortemente se o empréstimo pessoal seria a melhor saída. Em relação ao gênero carta, uma aluna pontuou que, apesar do formato, esta trouxe varios recursos para convencer o cliente.

Além disso, conforme colocou uma das alunas, se houvesse, por exemplo, somente os dados do empréstimo do banco, tal como no quarto balão da história em quadrinhos, informação que geralmente aparece em propagandas convencionais, o foco de atenção seria primordialmente o banco. No entanto, ao inserir uma história em quadrinhos, a propaganda foca também o cliente e suas necessidades e sonhos. 


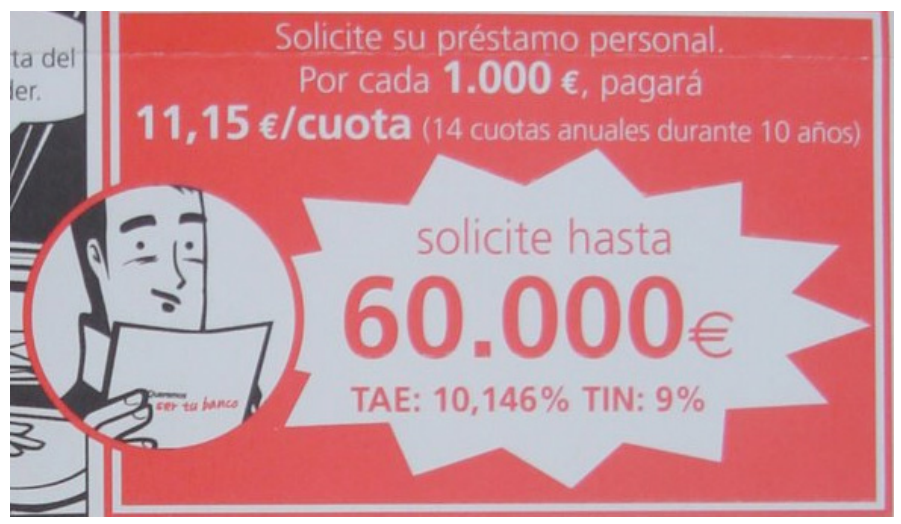

Figura 3: Propaganda Santander recortada Fonte: Elaborada pelos autores

No que concerne ao emprego das estratégias de leitura, verificamos que o texto permitiu aos alunos ativarem uma ampla gama de estratégias, aquelas que atuaram para uma compreensão dos componentes locais, aquelas que atuaram para a compreensão de componentes globais, o uso de predição de inferências e uma alta capacidade de apreciação e réplica em relação ao texto.

Em relação às dimensões de análise propostas por Sánchez Miguel, García Pérez e Rosales Pardo (2012), se levarmos em conta a dimensão quem, é possível constatar a autonomia dos alunos na elaboração do conteúdo, verificamos que para a dimensão como os alunos realizaram uma participação complexa, já que além da leitura em voz alta, interpretaram, estabeleceram relações entre o texto e a sua realidade por meio da análise de experiências. O conteúdo público (entendimento consensual do texto), dimensão quê foi de alta qualidade, haja vista que os alunos foram capazes desde o início de diferenciar a ideia principal das ideias secundárias, organizando-as de forma hierárquica. Acreditamos que esta atividade foi uma das que tiveram participação mais alta, a atividade aconteceu na maior parte do tempo centrada na figura dos alunos.

A realização da atividade de leitura anteriormente descrita reuniu em sua execução o protagonismo dos gêneros textual-discursivos pelo viés da hibridização, o que permitiu aos alunos uma participação ativa durante a realização das atividades de leitura coletiva e uma intensa 
negociação do significado, tendo enriquecido bastante o ensino e a aprendizagem da leitura em nível inicial.

\section{Considerações finais}

Parece bastante evidente ser benéfico para os alunos que os textos levados à sala de aula não se restrinjam a textos que seguem uma estrutura e propósitos convencionais, haja vista que é cada vez mais corrente o contato com gêneros textual-discursivos híbridos no mundo real, já que, da mesma forma que a língua sofre pressões de mudança, os gêneros também refletem tais pressões no sentido de buscar novas formas de se manifestar, tomando emprestada a estrutura de outro gênero, por exemplo, para atingir com mais intensidade os seus propósitos comunicativos.

Acreditamos que a construção da nossa proposta teve como efeito positivo o aumento do nível de consciência dos participantes a respeito do problema investigado. Na verdade, esta abordagem de leitura permitiu aos participantes um aumento do nível de consciência, respeito às dificuldades em se trabalhar com leitura nos semestres iniciais e como realizar um trabalho alternativo para sanar os problemas advindos da crença presente em boa parte dos manuais didáticos de língua espanhola, os quais insistem em desenvolver atividades de leitura, neste nível, que se limitem ao tratamento da compreensão superficial. Percebeu-se que a abordagem proposta pode ser mais dinâmica e acarretar o desenvolvimento de níveis profundos e crítico-reflexivos.

Estudar a linha entre estabilidade e instabilidade genérica tem-se mostrado bastante produtivo para entender não somente o comportamento dos produtores de texto, mas também o comportamento dos indivíduos que entrarão em interação com esses textos.

É necessário estudar as transformações genéricas não somente do ponto de vista teórico e, sim, do ponto de vista prático, buscando entender como os leitores reagem ao contato com gêneros híbridos e que estes se constituem uma excelente ferramenta para evidenciar a importância de uma abordagem de leitura que considere a importância não só da competência linguística e enciclopédica dos alunos para a construção dos sentidos do texto, mas também a importância da competência genérica. 


\section{Referências}

ADAM, J.-M.; HEIDEMANN, U. O texto literário: uma abordagem interdisciplinar. São Paulo: Cortez, 2011.

FIELD, M. L. Componentes visuais e a compreensão de textos. Trad. Rosana Sakugawa Ramos Cruz Gouveia. São Paulo: Special Book Services Livraria, 2004. (Portfolio SBS: reflexões sobre o ensino de idiomas; 10).

GENETTE, G. Palimpsestos: a literatura de segunda mão. Belo Horizonte: Edições Viva Voz, 2010.

LAZARINI, D. D. O gênero publicidade e a intergenericidade: práticas docentes e estratégias de ensino-aprendizagem de leitura na Educação de Jovens e Adultos (TESE)/ Dalcylene Dutra Lazarini. - 2013.

MARCUSCHI, L. A. Produção, análise de gêneros e compreensão. São Paulo: Parábola, 2008.

MATEUS, M.H. M. et al. Gramática da Língua Portuguesa. Lisboa: Caminho, 2003.

MORENO, C.; MORENO, V.; ZURITA, P. Nuevo avance básico. Madrid: SGEL, 2010.

SÁNCHEZ MIGUEL, E.; GARCÍA PÉREZ, J. R.; ROSALES PARDO, J. Leitura na sala de aula: como ajudar os professores a formar bons leitores. Porto Alegre: Penso, 2012.

VIGOTSKII, L. S.; LURIA, A. R.; LEONTIEV, A. N. Linguagem, desenvolvimento e aprendizagem. São Paulo: Ícone, 2001. 